\title{
Effects of Bi Addition on Si Features, Tensile Properties and Wear Resistance of Hypereutectic Al-15Si Alloy
}

\author{
Cleiton Luiz Pereira ${ }^{a}$ Leonardo Fernandes Gomes ${ }^{b}$, José Eduardo Spinelli ${ }^{a, b *}$ *(1) \\ ${ }^{a}$ Universidade Federal de São Carlos, Departamento de Engenharia de Materiais, \\ 13565-905, São Carlos, SP, Brasil. \\ ${ }^{b}$ Universidade Federal de São Carlos, Programa de Pós-Graduação em Ciência e Engenharia de \\ Materiais, 13565-905, São Carlos, SP, Brasil.
}

Received: March 18, 2020; Revised: April 11, 2020; Accepted: April 14, 2020.

\begin{abstract}
Bismuth (Bi) alloying in Aluminum ( $\mathrm{Al}$ ) alloys is considered of importance in special applications requiring improvements in the alloy machining. Despite that, the influence of Bi either on evolution of the solidification or on resulting microstructure of hypereutectic Al-Si alloys is still to be determined. The present research work is devoted to these requirements. In the present study, Al- $15 \mathrm{wt} . \% \mathrm{Si}$ hypereutectic alloy is modified with $1.0 \mathrm{wt} . \% \mathrm{Bi}$. The effects of this addition on the morphology of the phases forming the microstructure and on the tensile/wear properties are investigated. Various samples characterized by distinct cooling rates are generated by transient directional solidification of the ternary Al-Si-Bi alloy. Microstructure is examined by optical microscopy and scanning electron microscopy (SEM) analyses, segregation by energy-dispersive X-ray spectroscopy (EDS) whereas wear and tensile properties have been characterized by standardized tests. The experimental variations of the eutectic spacing are compared to each other based on their trends. It is found that the addition of minor Bi content ( 1 wt. \%) permitted tensile strength and ductility of $195 \mathrm{MPa}$ and $14 \%$. Furthermore, wear resistance is improved by up to $20 \%$ due to the $\mathrm{Bi}$ addition. The reasons for that will be outlined.
\end{abstract}

Keywords: Al-Si, Solidification, Microstructure, Tensile Properties, Wear.

\section{Introduction}

Al-Si alloys are widely used to produce shaped castings for a variety of applications as a result of their high specific strength, wear resistance, corrosion resistance and low thermal expansion coefficient. The usage of these alloys as an alternative to gray cast iron in automotive parts such as cylinder heads, brake discs and pistons aims to reduce automobile weight and improve fuel efficiency. The distribution of the primary and eutectic Si phases, as well as their size and morphology have a directly influence on the mechanical properties of Al-Si hypereutectic alloys. Additionally, adding silicon into the aluminum acts to improvement of the fluidity and hot tear resistance $\mathrm{e}^{1-3}$.

As potential substitutes for some applications where steels are still used, mainly in view of weight reduction and higher corrosion resistance, aluminium-based alloys have been more and more used during the years. In relation to the expanding applications of these alloys in the aeronautical and automotive industries, energy efficiency is directly associated to the weight factor, in which $\mathrm{Al}$ is about three times less dense than steel ${ }^{4,5}$.

Al-Bi alloys, may have immiscible phases and microstructures defined by a minority soft phase (Bi), following the morphology of fibers and/or droplets embedded into the Al-rich matrix. Practical applications include the fabrication of porous materials, electrical contact and self-lubricated bearings ${ }^{6}$. Tribological applications can be achieved in

*e-mail: spinelli@ufscar.br automotive components using aluminum alloys dispersed with bismuth. Such dispersions of low melting temperature elements decrease hardness and flow easily under sliding conditions?

During the wear process, while the Al-rich matrix provided some mechanical strength, the Bi-rich droplets were shown to act as self-lubricating agents, for Al-Bi alloys. The wear volume increases with an increase in the microstructural spacing $\left(\lambda_{\mathrm{B}}\right)$, as recently reported, for a same sliding distance for a monotectic $\mathrm{Al}-\mathrm{Bi}$ alloy. It means that in order to induce a higher wear resistance, a better dispersion of $\mathrm{Bi}$ droplets is required ${ }^{8}$.

Nowadays, $\mathrm{Al}$ industries have been progressing towards using recycled, or secondary, $\mathrm{Al}$ to reduce the initial energy output of the $\mathrm{Al}$ productive chain. The use of secondary $\mathrm{Al}$ causes some drawbacks mostly associated with elemental contamination. Due to that, understanding the effects of these additions has drawn researcher's attention. Bismuth (Bi) may be part of the composition of Al-Si alloys either as an addictive or a contamination. Hence, the microstructure aspects related to the presence of $\mathrm{Bi}$ are important requiring further consideration.

A bearing material with lower coefficient of friction as well as higher wear resistance is required for new car developments ${ }^{9}$. Systematic studies regarding ternary metallic alloys in comparison to the binary monotectic Al-base alloys remain scarce. To increase the ability of these materials to resist loads without fracturing, the addition of elements to $\mathrm{Al}$ 
alloys can contribute positively, as for instance Si. In order to realize the potential of a hypereutectic Al-Si alloy with Bi doping as bearing material, a deeper microstructure examination is required.

The present study aims to contribute to a better comprehension of the effects of cohesion, size and distribution of the hard and soft phases on the mechanical properties and wear behavior of the ternary Al-15wt.\%Si-1wt.\%Bi alloy. Upward directional unsteady-state solidification (DS) experiment was performed. This study focuses on the influence of solidification thermal parameters (growth rate and cooling rate) on the microstructural evolution. Quantitative measurements of the Bi fraction were performed. Samples from Al-Si-Bi alloy were subjected to advanced SEM-EDS technique to determine the main evolution of $\mathrm{Bi}$ and $\mathrm{Si}$ compositional profiles along the axial length of the DS casting. SEM images of the worn surfaces were further characterized. Experimental interrelations between the wear volume and the Si spacing will be outlined.

\section{Experimental Procedure}

To permit a transient heat flow condition to be achieved, a directional solidification system was used as detailed in previous articles ${ }^{10,11}$. Heat is directionally extracted through a water-cooled low carbon steel bottom, promoting vertical upward directional solidification. A stainless steel split mold was used having an internal diameter of $60 \mathrm{~mm}$, a height of $157 \mathrm{~mm}$ and a wall thickness of $5 \mathrm{~mm}$. To minimize radial heat losses, the vertical inner mold surface was covered with a layer of insulating alumina. Thin $(3 \mathrm{~mm}) 1020$ carbon steel was designed to close the bottom part of the mold. In the present experiments, the surface of the bottom part was ground by a \#1200 grinding wheel.

The Al-Si-Bi alloy was prepared by melting weighed quantities of aluminium, silicon and bismuth of high purity elements in a silicon carbide crucible inserted into an induction furnace. The following masses of elements were employed to produce the alloy: 1,399 $\mathrm{g}$ of Al, $249.8 \mathrm{~g}$ of Si and $16.7 \mathrm{~g}$ of $\mathrm{Bi}$. These elements were melted by using a $\mathrm{SiC}$ crucible inside an induction furnace. Both $\mathrm{Al}$ and $\mathrm{Si}$ were firstly added to be melted. Si was added in small pieces in order to be quickly incorporated into the molten Al. Afterwards, Bi was added to the molten bath. The adopted time $\mathrm{x}$ temperature cycle was enough to guarantee that all the Si dissolved in the alloy avoiding the microstructure to show any particle of raw Si. Furthermore, oxidation of Bi was greatly avoided.

The alloy was poured in the mold and the electric heaters were disabled so that directional solidification could be initiated, and at the same time, the controlled water flow was opened. During solidification, continuous temperature measurements in the casting were performed by fine type $\mathrm{K}$ thermocouples, with $1.6 \mathrm{~mm}$ diameter and 304 stainless steel sheath, placed along the casting length. The thermocouples were placed at positions (P) $5 \mathrm{~mm}, 10 \mathrm{~mm}, 15 \mathrm{~mm}, 20 \mathrm{~mm}$, $25 \mathrm{~mm}, 44 \mathrm{~mm}, 59 \mathrm{~mm}$ and $74 \mathrm{~mm}$ from the cooled bottom of the casting. The determination of solidification rates of cooling down was based in the passage of two isotherms along the length of the DS casting, which are liquidus and eutectic isotherms.
The cylindrical ingot was sectioned along its axial axis, sanded with a 1200 mesh sandpaper and etched with an acid solution (Poulton's reagent: $5 \mathrm{~mL} \mathrm{H}_{2} \mathrm{O}, 30 \mathrm{~mL} \mathrm{HNO}_{3}, 60 \mathrm{~mL} \mathrm{HCl}$ and $5 \mathrm{~mL} \mathrm{HF}$ ) to reveal the macrostructure. A solution of $\mathrm{HCl}$ in water was used to reveal the silicon particles for metallography. The $\mathrm{Si}$ and $\mathrm{Bi}$ spacings $\left(\lambda_{\mathrm{Si}}, \lambda_{\mathrm{Bi}}\right)$ were measured using optical microscopy's images by examining longitudinal sections of the casting. Furthermore, representative micrographs were obtained with an optical image processing system $^{12}$. The intercept method was employed to quantify the microstructural spacings with an average of 40 counting intercepts per position. This method is typically employed in the examination of longitudinal sections in the direction of heat flow, measuring the length between the center of a particular particle to another center aligned with the first ${ }^{13}$.

In addition, microstructural characterization was completed with a scanning electron microscopy (SEM), equipped with an energy dispersive spectrometer (EDS). An image processing software (ImageJ) was used to measure the fraction of $\mathrm{Bi}$ particles. Transverse sections along the axial length of the DS Al-Si and Al-Bi-Si samples were used in the micro-adhesive (ball crater) wear tests. A schematic representation of the used wear tester is shown in Reyes et al. ${ }^{8}$. To produce a wear crater, during the tests, a hard spherical bearing steel ball (AISI 52100, diameter of $25.4 \mathrm{~mm}$ and hardness of $818 \mathrm{HV}$ ) was rotated against the sample. The rotating ball is pressed into the sample from the top by test loads placed directly above the sample. The applied normal contact load was $0.9 \mathrm{~N}$ and the used ball speed was $0.33 \mathrm{~ms}^{-1}$ (250 RPM). Equation 1 was used to calculate the wear volume $V$, where $d$ is the crater diameter and $R$ is the ball radius ${ }^{8}$.

$$
V=\frac{\pi \cdot d^{4}}{64 \cdot R}
$$

The tests were carried out under dry sliding wear conditions to prevent any interfacial element from causing an influence. Features of the worn surfaces were assessed by using SEM. Chemical composition of the worn surfaces was examined by EDS. Transverse specimens were machined from different positions along the length of the DS casting. As such, tensile test samples according to specifications of ASTM Standard E $8 \mathrm{M}$ were prepared. A strain rate of about $3 \times 10^{-3} \mathrm{~s}^{-1}$ was adopted.

\section{Results and Discussion}

Characteristic microstructures of the examined alloy are shown in Figure 1. The lighter areas in each micrograph are the $\alpha$-Al phase, while the dark grey regions are the Si crystals forming eutectic structures. From the left to the right the images correspond to positions $(\mathrm{P})$ with increasing distance from the chill interface, that is $\mathrm{P}=2.5 \mathrm{~mm}, \mathrm{P}=10 \mathrm{~mm}$ and $\mathrm{P}=44 \mathrm{~mm}$. The morphology of $\mathrm{Si}$ shifted from fibers to lamellae at approximately $\mathrm{P}=3.0 \mathrm{~mm}$. From the thermocouple data in our directional solidification system the liquidus cooling rates related to these positions were determined as being $21.6 \mathrm{~K} / \mathrm{s}$, $11.6 \mathrm{~K} / \mathrm{s}$ and $1.1 \mathrm{~K} / \mathrm{s}$, respectively. At positions further from the chill interface (i.e., for lower cooling rates) it is worth noting that the size of the Si particles increases. This is thanks to the recurrent decrease of the liquidus growth velocity as a 


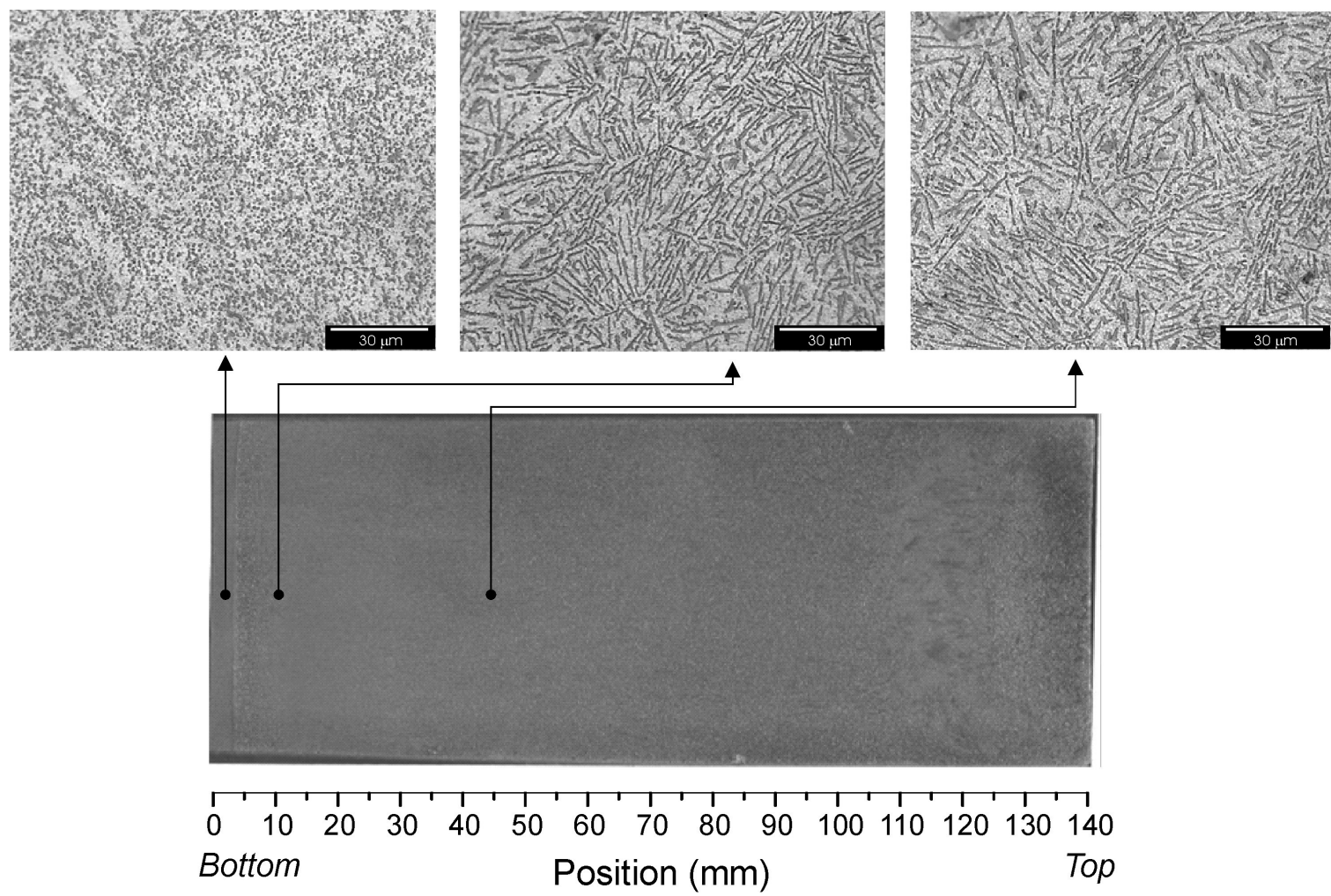

Figure 1. Directionally solidified macrograph of the Al-15 wt.\%Si-1.0 wt.\%Bi alloy with light micrographs related to specific positions along its length.

function of the length of the casting, i.e.; $2.3 \mathrm{~mm} / \mathrm{s}, 1.7 \mathrm{~mm} / \mathrm{s}$ and $0.5 \mathrm{~mm} / \mathrm{s}$, respectively.

The SEM images in Figure 2 were taken at a higher magnification and with the SEM in back-scatter electron (BSE) mode to show detailed aspects regarding either Bi or Si morphologies. The bright spots spread over the images in Figure 2 are $\mathrm{Bi}$ particles. Bi addition remains in its elemental form within the alloys. Near globular Bi droplets prevail along the examined microstructures. The shape of the Si particles can be better evaluated through the deep etched SEM images in Figure 2. From this visualization, the microstructures of the Al-15 wt.\%Si-1.0 wt.\%Bi alloy displayed $\mathrm{a}(\alpha \mathrm{Al}+\mathrm{Si})$ eutectic structure in association with Bi. Although Si morphology of the eutectic structure for the tested alloy was found to be predominantly lamellar across the casting length, higher cooling rates induced structural modifications in the eutectic Si phase, which transitioned to fibers for cooling rates higher than $22 \mathrm{~K} / \mathrm{s}$. This key value is roughly two-fold higher than that observed in the Al- $15 \mathrm{wt} . \% \mathrm{Si}$ alloy, whose presence of fibers + globules was observed for rates exceeding $9 \mathrm{~K} / \mathrm{s}$ during the formation of eutectic $\mathrm{Si}^{14}$.

Figure 3 shows the variations found for both $\lambda_{\mathrm{Bi}}$ and $\lambda_{\mathrm{Si}}$ along the casting length. For the variations of $\lambda_{\mathrm{Bi}}$ and $\lambda_{\mathrm{Si}}$ in the ternary alloy, single relationships following $-1 / 2$ function exponent for the eutectic velocity $\left(\mathrm{V}_{\mathrm{F}}\right)$ are appropriate to represent the experimental data generated, as can be seen in Figure $3 \mathrm{a}$ and $3 \mathrm{~b}$. The experimental expression reported by Reyes et al. ${ }^{14}$ for the binary Al- $15 \mathrm{wt} . \% \mathrm{Si}$ alloy is $\lambda_{\mathrm{Si}}=1.3\left(\mathrm{v}_{\mathrm{E}}\right)^{-1 / 2}$, which is very close to that found for the
Bi-containing alloy in Figure 3a. It appears that doping with $\mathrm{Bi}$ is not able to change significantly the Si spacing. Both microstructure spacings $\lambda_{\mathrm{Bi}}$ and $\lambda_{\mathrm{Si}}$ vary with growth rate. The best distributions of either $\mathrm{Si}$ or $\mathrm{Bi}$ can be seen for higher growth velocities. This is explained due to the lower spacing values under such conditions.

Both Bi area fraction and Bi content increase with the transient upward movement of the solidification front while the $\mathrm{Si}$ content remains practically unaltered, as can be seen in Figure 4. It seems that $\mathrm{Bi}$ is pushed to the $\mathrm{Al} / \mathrm{Si}$ front during solidification enriching the interdendritic region with $\mathrm{Bi}$. The accumulation of Bi promoted the development of perfectly rounded edges as shown by the arrows in the magnified inset image of Figure 2. The complex skeleton arrangement is mainly formed by lamellar $\mathrm{Si}$ as also described by Farahany et al. ${ }^{15}$.

As can be seen in Figure 5, the ultimate tensile strength $\left(\sigma_{u}\right)$ and the strain to failure $(\delta)$ vary along the length of the DS Al-Si-Bi alloy casting (square and circle points, respectively) with unaltered values for $\lambda_{\mathrm{Si}}{ }^{-1 / 2}<0.6$. As previously demonstrated, the quantified aspects of the microstructure $\left(\lambda_{\mathrm{Si}}, \lambda_{\mathrm{Bi}}\right)$ are related to the various cooling rates and growth rates determined for the solidified samples (see Figure 3). Only lamellar $\mathrm{Si}$ samples were considered for tensile tests. This is because the region containing fibers was very confining to the very beginning of the casting (first $2.5 \mathrm{~mm}$ ), which avoided its examination by using the current tensile test configurations. Considering that the major 


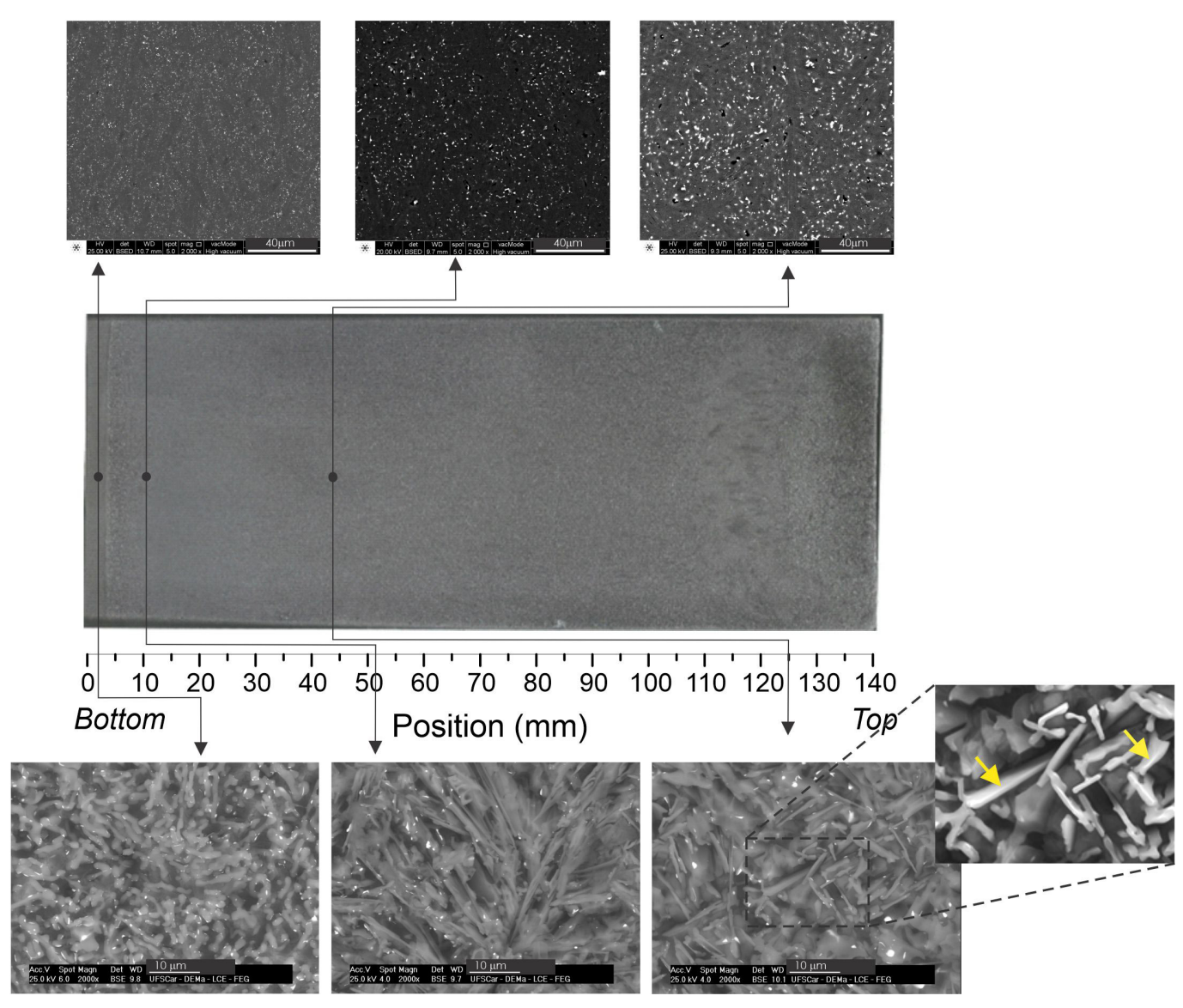

Figure 2. SEM images showing details of the microstructure found in the Al-15 wt. $\% \mathrm{Si}-1.0 \mathrm{wt} . \% \mathrm{Bi}$ alloy. The upper row shows the Bi droplets while the lower set of images highlights the Si particles.

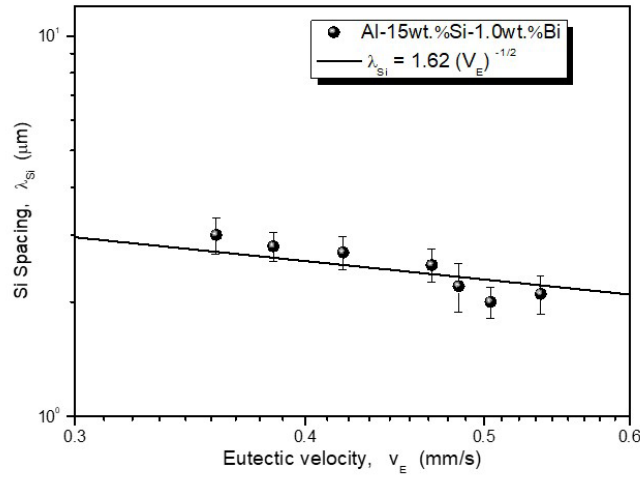

(a)

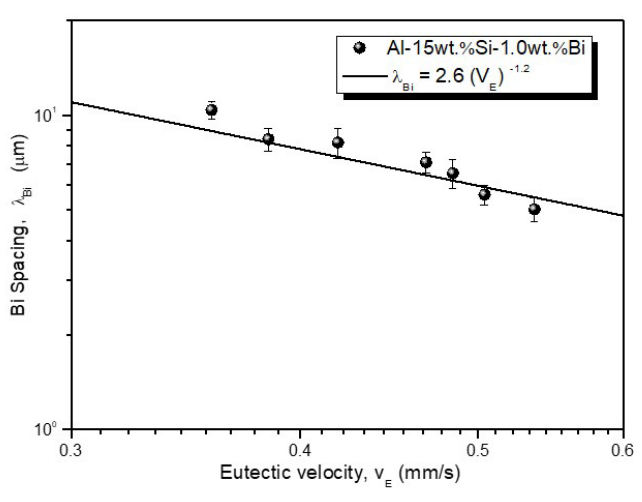

(b)

Figure 3. (a) $\lambda_{\mathrm{Si}}$ and (b) $\lambda_{\mathrm{Bi}}$ as a function of the eutectic growth velocity $\mathrm{v}_{\mathrm{E}}$.

microstructural characteristic constituting the samples is the spacing of the eutectic structure, $\lambda_{\mathrm{Si}}$, a method was required to describe the scale variation analysis of the spacing affecting the strength and ductility. Therefore, the application of "Hall-Petch" relationships to compare the present results with the previous results for binary the Al-15 wt.\%Si was adopted ${ }^{14}$.
In general, the tensile properties of the alloy containing Al-15 wt.\% Si -1.0 wt.\%Bi are higher. The behavior of the strength here is in agreement with that reported by Biswas et al. ${ }^{16}$. This means that the addition of $\mathrm{Bi}$ in hypereutectic $\mathrm{Al}-\mathrm{Si}$ alloys promotes increase in the alloy strength. The positive effect of $\mathrm{Bi}$ is very clear if one compares the Hall-Petch plots for ternary and binary compositions in Figure 5. The prevalence 

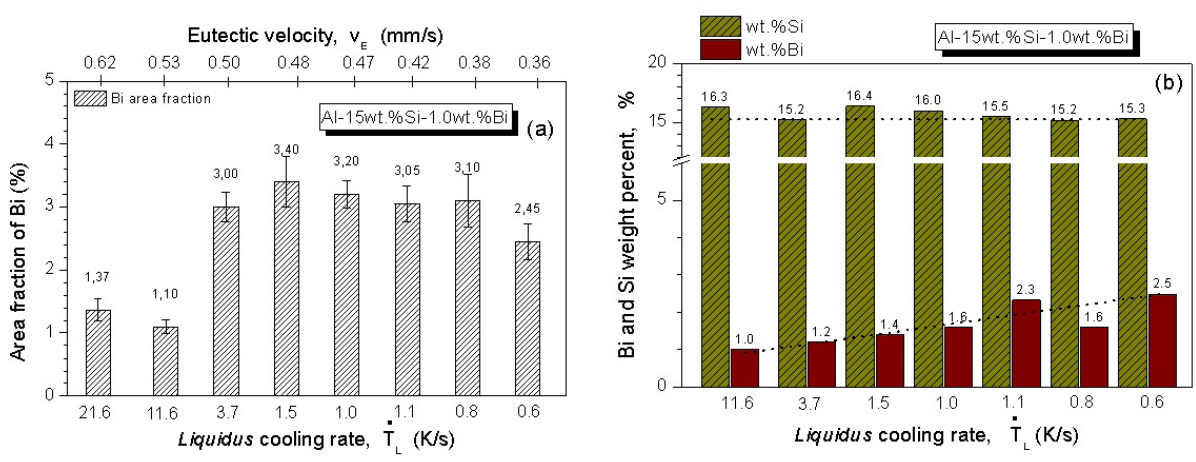

Figure 4. (a) Area fraction of Bi and (b) Bi / Si EDS macrosegregation profiles for the Al-15 wt.\%Si-1.0 wt.\%Bi alloy.
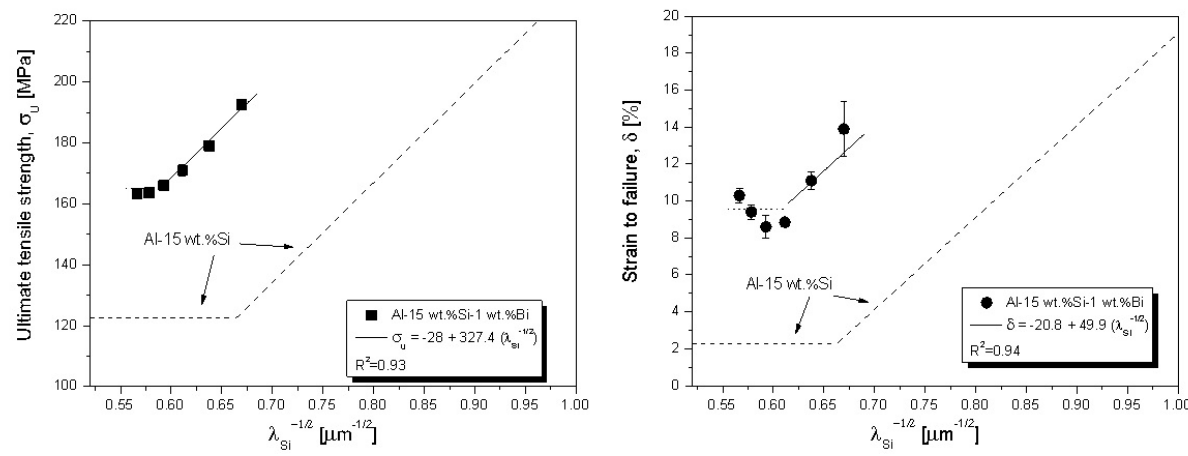

Figure 5. Evolutions of ultimate tensile strength and strain to failure along the length of the $\mathrm{DS} \mathrm{Al}-15 \mathrm{wt} . \% \mathrm{Si}-1.0 \mathrm{wt}$. \% Bi alloy as a function of the inverse of the square root of the Si spacing, $\lambda_{\mathrm{Si}}{ }^{-1 / 2} \cdot \mathrm{R}^{2}$ is the coefficient of determination related to the adjusted curves.

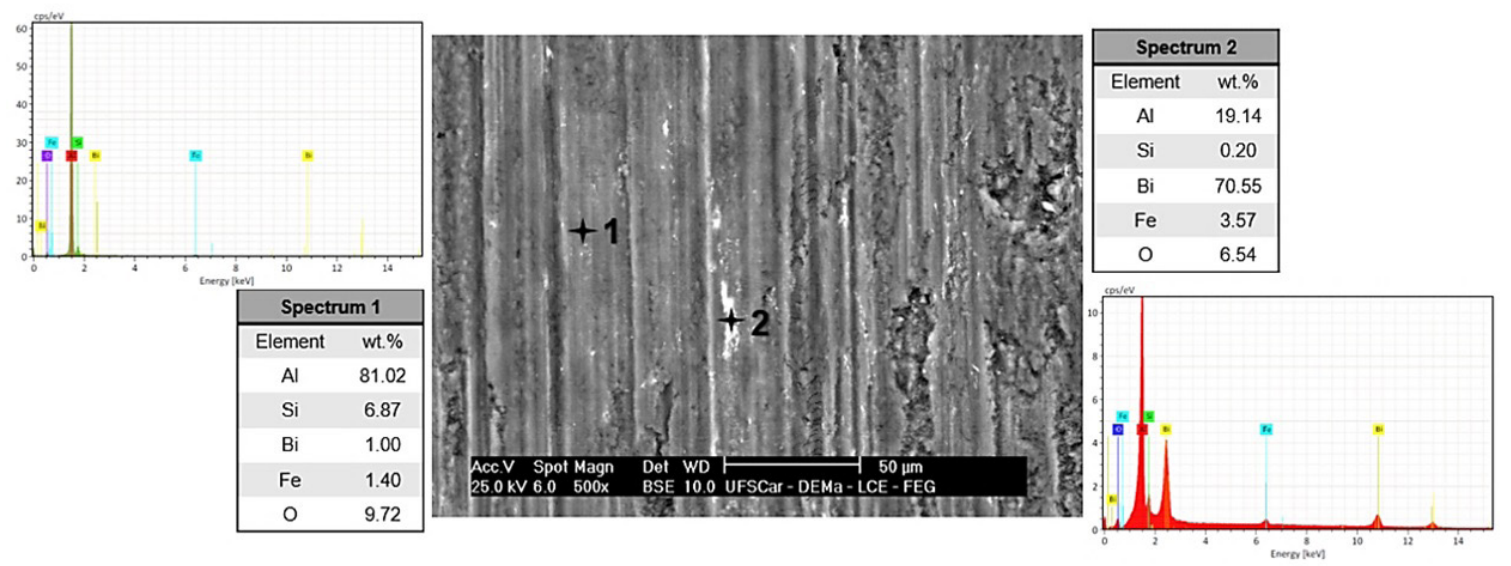

Figure 6. SEM image of the worn surface and EDS compositions of Bi-rich (Spectrum 2) and Al-rich (Spectrum 1) areas. It shows the action of the solid lubricant (brighter areas) which has been spread by the rotating ball.

of lamellar instead of flaky structure is the main reason for increasing strength.

The highest $\sigma u$ and $\delta$ of $195 \mathrm{MPa}$ and $14 \%$ for the ternary Al-15 wt. \%Si - 1.0 wt.\%Bi alloy casting are associated with fine lamellar microstructural spacings. Better distribution of either $\mathrm{Si}$ or Bi resulted in augmentation of the tensile properties. The $\lambda_{\mathrm{Si}}$ related to those properties is $2.2 \mu \mathrm{m}$ for the ternary alloy. In order to achieve the same properties for the same alloy without $\mathrm{Bi}$ addition a $\lambda_{\mathrm{Si}}$ of $1.3 \mu \mathrm{m}$ is required. Furthermore, $\mathrm{Bi}$ inhibits the propagation of cracks through the grain boundaries of $\alpha$-Al phase, reducing the premature fracture of the Si particles. This could improve the ductility.

Figure 6 shows a representative SEM image of the surface morphology after wear test. Two points were chosen to be examined by using SEM-EDS instrument. The Al/Si eutectic constituent (Spectrum \#1) is subjected to distortion while the spread Bi-rich layers (brighter areas - Spectrum \#2) behave as a solid lubricant on the friction surface. As the test develops, soft particles of Bi tend to form a solid lubricant layer on the sliding metal contact. However, the wear contact may change from adhesive 


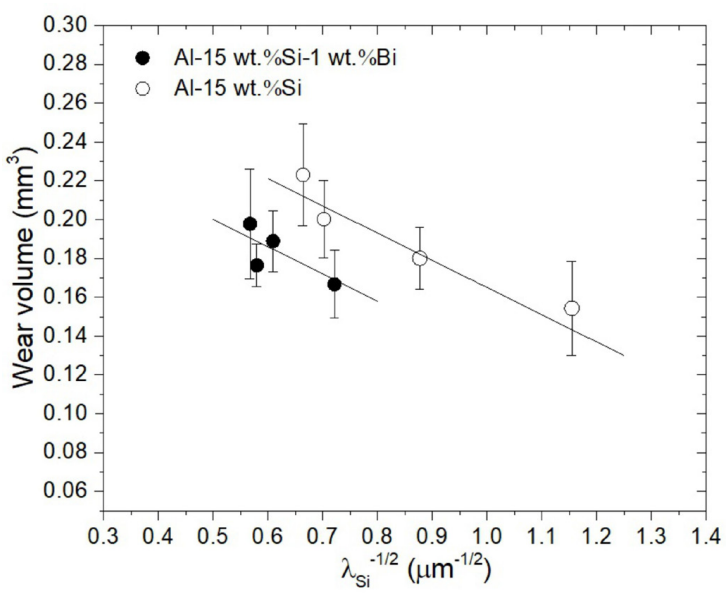

Figure 7. Experimental variation of wear volume with the Si spacing measured in the Al-15 wt.\%Si and Al-15 wt.\%Si-1 wt.\%Bi alloys samples for a test time of 30 minutes (i.e., $598.2 \mathrm{~m}$ ).

to abrasive as soon as $\mathrm{Fe}$ and $\mathrm{Al}$ oxides form, as can be inferred examining the EDS data of the spectra. Fe comes from the used steel ball for the tests.

The experimental results of wear volume, $\mathrm{V}$, as a function of $\lambda_{\mathrm{Si}}$ for both tested alloys can be seen in Figure 7 for 30 minutes of wear tests. This time corresponds to a sliding distance of $598.2 \mathrm{~m}$ during the wear test of each sample. The points are experimental results of each alloy while the lines represent the best fittings to the experimental points.

The variations of wear volume can be considered significant in both cases with higher volumes being related to the alloy without Bi doping. For such range of microstructures, it can be seen that the wear volume, $\mathrm{V}$, decreases with the decrease in $\lambda_{\mathrm{Si}}$. A more homogeneous distribution of Si particles appears to be beneficial to the wear. It seems that the higher strength provided by the addition of Bi interferes in the wear behavior. The same was demonstrated by Kang et al. ${ }^{17}$. As a consequence, higher wear resistance is attained for Bi-modified samples. Furthermore, a more homogeneous distribution of $\mathrm{Bi}$ droplets in the microstructure is beneficial to lower the wear volume.

\section{Conclusions}

After a complete characterization of the microstructure associated with the directional solidification of the ternary Al-15 wt.\%Si-1 wt.\%Bi alloy for a range of cooling rates, the following major conclusions were attained:

- The microstructure of the DS Al-15 wt.\%Si-1.0 wt.\%Bi alloy was shown to be characterized by a predominantly lamellar $(\alpha \mathrm{Al}+\mathrm{Si})$ eutectic mixture with near globular Bi droplets;

- For samples solidified at higher cooling rates it was found that the eutectic Si morphology started to become fibrous. The critical cooling rate for that micromorphology was $22 \mathrm{~K} / \mathrm{s}$;

- Experimental scaling laws are proposed relating the $\lambda_{\mathrm{Si}}$ to the eutectic velocity $\left(\mathrm{v}_{\mathrm{E}}\right)$ for both Al-Si and Al-Si-Bi alloys. The $-1 / 2$ exponent from the
Jackson-Hunt approach was verified as viable to characterize the experimental $\lambda_{\mathrm{Si}} \times \mathrm{v}_{\mathrm{E}}$ trends.

- The Si particles forming the eutectic mixture of the Bi containing alloy was found to have rounded edges. Furthermore, Bi segregates to the $\mathrm{Al} / \mathrm{Si}$ front resulting in enrichment of the farther positions from the cooled surface of the casting;

- The addition of Bi in hypereutectic Al-Si alloy was shown to promote important increase in the alloy tensile properties as well as in the wear resistance. Hall-Petch functions were able to represent relationships of the ultimate tensile strength, strain-to-failure and wear volume with $\lambda_{\mathrm{Si}}$ for both examined Al-Si and Al-Si-Bi alloys.

\section{Acknowledgements}

The authors are grateful to FAPESP- São Paulo Research Foundation, Brazil (grant 2017/12741-6); Capes- Coordenação de Aperfeiçoamento de Pessoal de Nível Superior, Brazil (Funding Code 001); and CNPq- National Council for Scientific and Technological Development, Brazil.

\section{References}

1. Cruz KS, Meza ES, Fernandes F A P, Quaresma JMV, Casteletti LC, Garcia A. Dendritic arm spacing affecting mechanical properties and wear behavior of Al-Sn and Al-Si alloys directionally solidified under unsteady-state conditions. Metall Mater Trans, A Phys Metall Mater Sci. 2010;41(4):972-84. http://dx.doi.org/10.1007/s11661-009-0161-2.

2. Jeon JH, Shin JH, Bae DH. Si phase modification on the elevated temperature mechanical properties of Al-Si hypereutectic alloys. Mater Sci Eng A. 2019;748:367-70. http://dx.doi.org/10.1016/j. msea.2019.01.119.

3. Lv G, Bao Y, Zhang Y, He Y, Ma W, Lei Y. Effects of electromagnetic directional solidification conditions on the separation of primary silicon from Al-Si alloy with high $\mathrm{Si}$ content. Mater Sci Semicond Process. 2018;81:139-48. http:// dx.doi.org/10.1016/j.mssp.2018.03.006.

4. Kamberovic Z, Romhanji E, Filipovic M, Korac M. The recycling of high magnesium aluminium alloys: estimation of the most reliable procedure. J Metall. 2009;15:189-200.

5. Miller W, Zhuang L, Bottema J, Wittebrood A, De Smet P, Haszler A, et al. Recent development in aluminium alloys for the automotive industry. Mater Sci Eng A. 2000;280(1):37-49. http://dx.doi.org/10.1016/S0921-5093(99)00653-X.

6. Freitas ES, Silva AP, Spinelli JE, Casteletti LC, Garcia A. Inter-relation of microstructural features and dry sliding wear behavior of monotectic Al-Bi and Al-Pb alloys. Tribol Lett. 2014;55(1):111-20. http://dx.doi.org/10.1007/s11249-0140338-8.

7. Silva AP, Spinelli JE, Garcia A. Microstructural evolution during upward and downward transient directional solidification of hypomonotectic and monotectic Al-Bi alloys. J Alloys Compd. 2009;480(2):485-93. http://dx.doi.org/10.1016/j. jallcom.2009.01.105.

8. Reyes RV, Pinotti VE, Afonso CRM, Casteletti LC, Garcia A, Spinelli JE. Processing, As-cast microstructure and wear characteristics of a monotectic Al-Bi-Cu alloy. J Mater Eng Perform. 2019;28(2):1201-12. http://dx.doi.org/10.1007/ s11665-018-3851-3.

9. Ratke L, Diefenbach S, Drees S, Alkemper J, Prinz B, Romero A, et al. Multi-droplet Marangoni motion in immiscible Al-Si-Bi 
alloys: results of a D-2 experiment. Adv Space Res. 1995;16(7):18590. http://dx.doi.org/10.1016/0273-1177(95)00157-A.

10. Costa TA, Freitas ES, Dias M, Brito C, Cheung N, Garcia A. Monotectic Al-Bi-Sn alloys directionally solidified: effects of Bi content, growth rate and cooling rate on the microstructural evolution and hardness. J Alloys Compd. 2015;653:243-54. http://dx.doi.org/10.1016/j.jallcom.2015.09.009.

11. Canté MV, Spinelli JE, Cheung N, Garcia A. The correlation between dendritic microstructure and mechanical properties of directionally solidified hypoeutectic Al-Ni alloys. Met Mater Int. 2010;16(1):39-49. http://dx.doi.org/10.1007/s12540-010-0039-2.

12. Brito C, Costa TA, Vida TA, Bertelli F, Cheung N, Spinelli JE, et al. Characterization of dendritic microstructure, intermetallic phases, and hardness of directionally solidified Al-Mg and Al-Mg-Si alloys. Metall Mater Trans, A Phys Metall Mater Sci. 2015;46(8):334255. http://dx.doi.org/10.1007/s11661-015-2967-4.

13. Gündüz M, Çadırlı E. Directional solidification of aluminiumcopper alloys. Mater Sci Eng A. 2002;327(2):167-85. http:// dx.doi.org/10.1016/S0921-5093(01)01649-5.
14. Reyes RV, Kakitani R, Costa TA, Spinelli JE, Cheung N, Garcia A. Cooling thermal parameters, microstructural spacing and mechanical properties in a directionally solidified hypereutectic Al-Si alloy. Philos Mag Lett. 2016;96(6):228-37. http://dx.doi. org/10.1080/09500839.2016.1192297.

15. Farahany S, Ourdjini A, Bakar T A A, Idris MH. On the refinement mechanism of silicon in $\mathrm{Al}-\mathrm{Si}-\mathrm{Cu}-\mathrm{Zn}$ alloy with addition of bismuth. Metall Mater Trans, A Phys Metall Mater Sci. 2014;45(3):1085-8. http://dx.doi.org/10.1007/s11661-0132158-0.

16. Biswas P, Prasadu KD, Mondal MK. Effect of Bi addition on microstructure and mechanical properties of hypereutectic Al-17.6Si alloy. Mater Res Express. 2019;6(11):1165b9. http:// dx.doi.org/10.1088/2053-1591/ab4d34.

17. Kang N, Coddet P, Liao H, Baur T, Coddet C. Wear behavior and microstructure of hypereutectic Al-Si alloys prepared by selective laser melting. Appl Surf Sci. 2016;378:142-9. http:// dx.doi.org/10.1016/j.apsusc.2016.03.221. 